\title{
The use of allogenic and autologous tissue to treat aortic valve endocarditis
}

\author{
Francesco Nappi ${ }^{1}$, Sanjeet Singh Avtaar Singh ${ }^{2}$, Mario Lusini $^{3}$, Antonio Nenna ${ }^{3}$, Ivancarmine Gambardella ${ }^{4}$, \\ Massimo Chello
}

${ }^{1}$ Department of Cardiac Surgery, Centre Cardiologique du Nord, Saint-Denis, Paris, France; ${ }^{2}$ Department of Cardiac Surgery, Golden Jubilee National Hospital, Glasgow, UK; ${ }^{3}$ Department of Cardiovascular Surgery, Università Campus Bio-Medico di Roma, Rome, Italy; ${ }^{4}$ Department of Cardiothoracic Surgery, Weill Cornell Medicine, New York, NYUSA

Contributions: (I) Conception and design: F Nappi, SSA Singh; (II) Administrative support: F Nappi, M Chello; (III) Provision of study materials or patients: F Nappi, SSA Singh, M Lusini, I Gambardella; (IV) Collection and assembly of data: F Nappi, SSA Singh, M Lusini, A Nenna, I Gambardella; (V) Data analysis and interpretation: F Nappi, SSA Singh, A Nenna, M Lusini, I Gambardella; (VI) Manuscript writing: All authors; (VII) Final approval of manuscript: All authors.

Correspondence to: Francesco Nappi, MD. Department of Cardiac Surgery, Centre Cardiologique du Nord, 36 Rue des Moulins Gémeaux, 93200 Saint-Denis, Paris, France. Email: francesconappi2@gmail.com.

\begin{abstract}
The surgical treatment of aortic valve endocarditis (AVE) is generally performed using conventional mechanical or biological xenograft prosthesis, with limited use of aortic homograft (Ao-Homo) or pulmonary autograft (PA). Clinical evidence has demonstrated a clear contradiction between the proven benefits of Ao-Homo and PA in the context of infection and the very limited use of allogenic or autologous tissue in everyday clinical practice. This review aims to summarize the most recent and relevant literature in order to foster the scientific debate on the use of the use of allogenic and autologous tissue to treat AVE. The decisional process of the Heart Team should also include the preferences of the patient, his/her family, the general cardiologist or primary care physician. The use of allogenic or autologous valve substitute is beneficial if there is a high risk of recurrence of infection, avoiding extensive adhesiolysis and debridement of synthetic material. In any case, those procedures should be performed by highly trained centers to optimize outcomes.
\end{abstract}

Keywords: Aortic valve; endocarditis; allogenic; autologous; homograft

Submitted Jul 28, 2019. Accepted for publication Aug 15, 2019.

doi: $10.21037 /$ atm.2019.08.76

View this article at: http://dx.doi.org/10.21037/atm.2019.08.76

\section{Introduction}

The incidence of infective endocarditis (IE) is about $3-10$ per 100,000 people ranging from $35 \%$ (1) to $39.1 \%$ (2) in patients with native aortic valve involvement and from $56 \%$ (1) to $64.4 \%$ (2) in those who have had previous aortic valve surgery. For these reasons, surgical treatment of aortic valve endocarditis (AVE) and the choice of an ideal substitute are often decisive in the resolution of the disease. Over the decades, the challenges associated with aortic valve IE have become increasingly demanding because the patients affected are older with a multitude of comorbidities (3). This population in high-income countries are often infected by virulent staphylococci that have obscured the strains of penicillin-sensitive streptococci $(4,5)$. The source of the infections responsible for staphylococcal bacteremia is found with increased use of long-term intravenous lines and invasive procedures required for cardiac device implantation (permanent pacemakers, implantable cardioverter defibrillators) (6). In younger patients, the use of intravenous drugs and congenital heart disease have replaced rheumatic heart disease as the main risk factors for aortic IE (7). Likewise, transcatheter valve replacement has revolutionized the management of valvular heart disease 
despite the potential that it may be associated with higher rates of IE than surgically implanted prosthetic valves (8).

The surgical treatment of AVE today is generally performed using conventional mechanical or stented/ non-stented xenograft prosthesis, although surgeons sometimes prefer the use of aortic homograft (Ao-Homo) or pulmonary autograft (PA) (9). Clinical evidence has demonstrated a clear contradiction between the proven benefits of Ao-Homo and PA in the context of infection and the very limited use of allogenic or autologous tissue in everyday clinical practice $(9,10)$. Moreover, recurrence of infection after valve replacement for IE is a major concern, and accordingly, the optimal valve substitute in this setting has been debated for decades (10-13). The biological substitute remains ideal for certain subgroups of young patients, women with future plans of pregnancy or any other contraindication to anticoagulants $(9,14-17)$, with the caveat of an increased risk of early structural valve degeneration (SVD) (18-20). This category of patient constitutes a point of reference for the use of a homograft or an autograft as an aortic valve substitute in the context of infection because both guarantee excellent hemodynamic performance while avoiding the need for life-long vitamin K-antagonists. However, a reluctance among surgeons to Ao-Homo or PA usage can be explained by the paucity of randomized trials affirming the clinical benefit of allogenic tissues in these categories of patients compared to observational studies $(10,14)$.

\section{Clinical evidence}

\section{Professional society recommendations and surgical choices}

The use of Ao-Homo is recommended by the position papers of professional societies predominantly on the basis of large observational studies that have reported a benefit with regards to outcomes in infectious endocarditis (9,15-20). Guidelines from The Society of Thoracic Surgeons assigned a Class IIb recommendation (level of evidence B) to the use of Ao-Homo in IE. The choice of allogenic tissue is considered reasonable for native/ prosthetic AVE particularly with periannular abscess and extensive annular or aortic wall destruction requiring aortic root replacement or reconstruction, as well as in cases of extensive aortic-ventricular discontinuity $(21,22)$. The AATS 2016 guidelines echo these recommendations indicating the use of allogenic or autologous tissue in destructive native or prosthetic aortic valve IE which surgery of aortic root; however, the choice of prosthetic bioroot or prosthetic valved conduit with a mechanical or bioprosthetic valve are considered acceptable alternatives although it should be guided by the grade of surgeon's training and experience (22). The degree of infectious involvement of annulus and aorto-mitral curtain are factors that warrant a bespoke surgical strategy (23-25). Furthermore, the involvement of the aortic annulus is also possible with an IE that is limited to a single leaflet requiring precise removal of vegetation as well as aggressive debridement of necrotic material (23-25). This concern is also highlighted in the guidelines when the use of mechanical and stented xenograft is advocated in complex IE and periannular abscess formation provided the valve can be anchored securely to healthy and strong tissue (class IIa level of evidence B). Conversely, the use of homograft or PA has been considered the most appropriate treatment and it is preferable to implantation of a prosthetic valved conduit in case of complex infectious lesions involving native valve or prosthetic valve endocarditis (PVE) in which extensive annular destruction and invasion of the heart structure is noted $(21,22)$. In these patients, radical surgery involving root reconstruction is required with the use of allogenic or autologous substitute. In the presence of IE extending to the aorto-mitral junction with injury of mitral valve and trigonal zone, the choice of double aorto-mitral homograft is suitable either using a monobloc implant or separate bloc with partial mitral homograft insertion (26,27). Despite the recommendations of professional societies, allogeneic or autologous tissue has not been widely promoted, in either patients with an AVE that requires emergency or urgent surgical intervention nor those who are scheduled for an elective intervention. One of the reasons for their limited use is that the superior clinical outcomes associated with the choice of allogenic and autologous tissue for aortic valve replacement (AVR), that has been highlighted in several observational studies $(9,15-17)$, have not been subsequently confirmed in randomized controlled trials (28). This concern is well highlighted in the guidelines where both of these recommendations for the choice of homograft or autograft are categorized as Class II, indicating that there is conflicting evidence and/or a divergence of opinion related to the usefulness/efficacy of this procedure or treatment. The usefulness and efficacy of Ao-Homo or PA is less well established by evidence/opinion (categorized as Class IIb) because data are derived from a single randomized trial or from nonrandomized studies (Level of evidence B) $(21,22,28,29)$. 

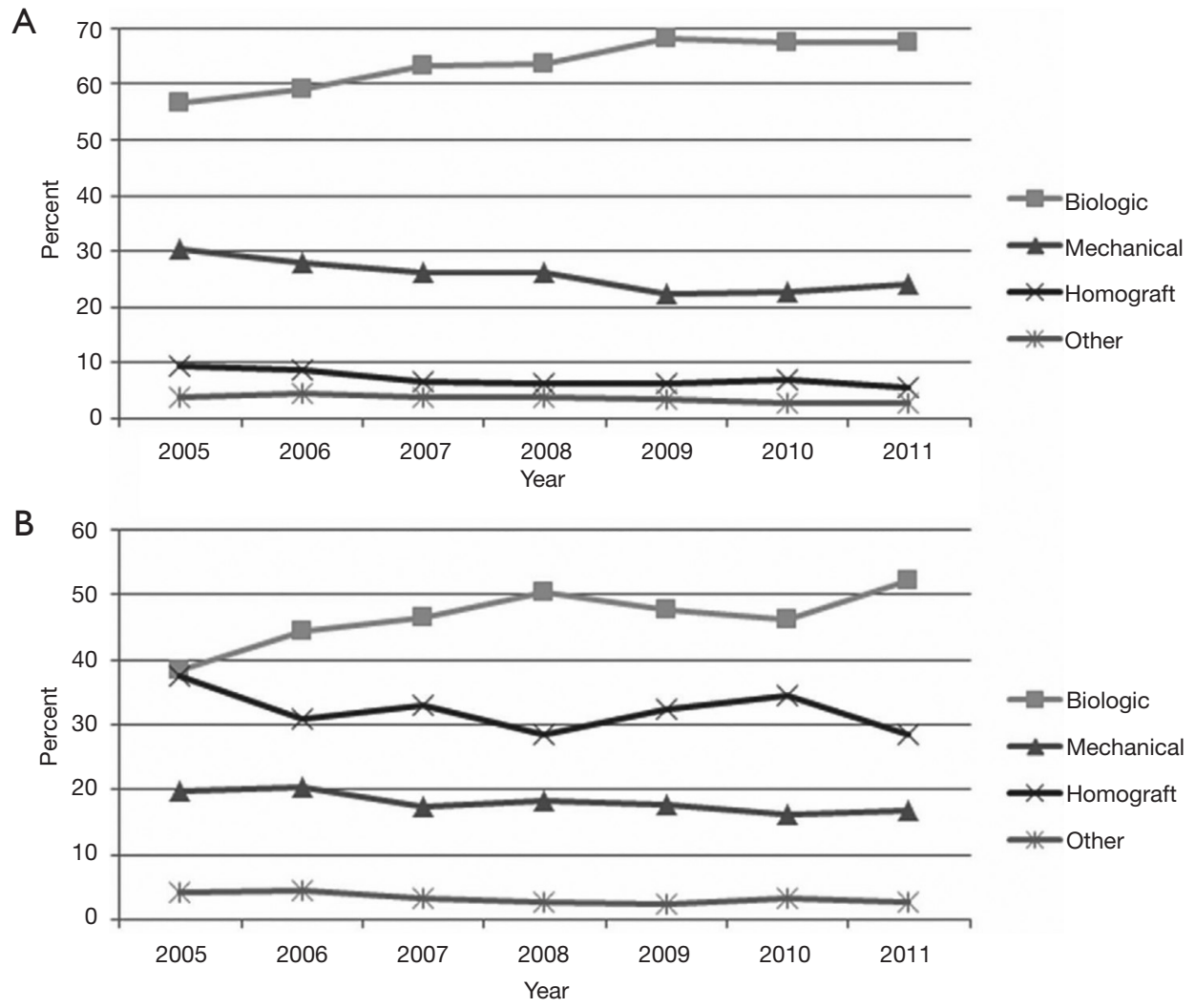

Figure 1 Trend representing the use of substitutes for AVR in endocarditis from 2005 to 2011 in USA (STS database). (A) Native aortic valve endocarditis and (B) Prosthetic valve endocarditis. The $\mathrm{P}$ value for the usage trends in both groups was $<0.001$. (biologic $=$ squares; mechanical $=$ triangles; homograft $=\mathrm{x}$; other $=$ star). Reproduced with permission from Savage et al. Ann Thorac Surg 2014;98:806-14.

\section{Clinical use}

\section{Ao-Homo}

In patients with active endocarditis who require complex aortic valve surgery, the recurrence of infection rate varies from $2 \%$ in recipients of allogenic tissue as reported by Fukushima et al. (16) up to $25.4 \%$ in those who receive a conventional prosthesis in the first year after implantation as documented in a pivotal study by Musci et al. (30). The clinical and echocardiographic evidence of recurrent aortic IE has been reported within the first year in several observational studies (1,30-33). Active endocarditis is a statistically significant risk factor for increased early $(1,9,30,31,33)$ and late mortality (1,9,15-17,30-32,34). In recent years, the choice of polyester graft in situ of an infectious injury has gained traction amongst cardiac surgeons for satisfactory outcomes reported with improvements in antibiotic therapy (35). The limited use of allogeneic and autologous tissue may be due to the renewed enthusiasm for antibiotic therapy before surgery for some cases of PVE (35), avoiding urgent operations (3). Some authors from Harvard Medical School $(31,33)$ reported a significant increase in the proportion of patients treated with allogenic tissue when abscess formation occurs (67\% vs. $41 \%$ for mechanical valve and $30 \%$ for xenograft valves, $\mathrm{P}<0.001)$ or when the methicillin-resistant Staphylococcus was detected (26\% vs. $13 \%$ for mechanical prosthesis and $12 \%$ for xenograft). This allows us to infer that the Ao-Homo or PA tissue is more likely used in patients with active and severely complicated endocarditis with/without involvement of the heart structure (31). In our experience, the homograft for replacement for aortic and mitral valve disease was used in $56.2 \%$ and $21 \%$ of patients with active endocarditis who developed periannular abscess and aortic root involvement $(9,26)$ (Figure 1).

Steffen et al. (36) reported the considerable microbiological advantages of allogeneic tissues in extensive infections of the heart structure, either in native or PVE. 
The authors revealed that Ao-Homo tissue treated during cryopreservation process maintains some antibacterial activity over 5 years. Several combinations of antibiotics were tested on cryopreserved allogeneic tissue (gentamicin, piperacillin, vancomycin, metronidazole, amphotericin B, flucloxacillin, meropenem, tobramycin and colistin) and have significant influence on their infection resistance. Ascending Ao-Homo tissue have enhanced bacterial resistance against staphylococcal bacteria (S. epidermidis and $S$. aureus) with less bacterial contamination compared to homograft aortic valves. A more effective resistance was found against $P$. aeruginosa using flucloxacillin and E. coli with meropenem and colistin (36). Application of antibiotic after thawing the cryopreserved Ao-Homo significantly decreases the recurrence of infections compared to conventional prostheses or Dacron graft in whereby this benefit has not yet been clearly demonstrated (37). Although the risk of vascular graft infection is reduced by pre-treating the prostheses with antibiotics $(38,39)$, the antibiotic/fibrin compound showed a favorable effect of delayed release of antibiotics in the early prevention of the endocarditis recurrence (39). Furthermore, a better understanding of effective concentrations of $\beta$-lactam antibiotics may enhance this action by conferring additional immunity to recurrence of infection (39). The better response of allogeneic tissue to antibiotics has been shown in reports where Ao-Homo implants were successfully treated medically after relapse of infection (15-17).

\section{$P A$}

The choice of PA as an aortic valve substitute in the setting of IE has important implications for long-term outcomes and should be carefully selected for specific patients $(40,41)$. In high-income countries, the majority of patients undergoing AVR for IE are elderly $(4,5)$, so surgery of infective aortic valve disease is recommended using bioprosthetic valves (21). By contrast, in some categories of younger patients-such as intravenous drug abusers, previous congenital heart disease, woman with future plans of pregnancy and people with longer life expectancy-who develop IE of aortic valve, the ideal substitute for AVR should provide durable hemodynamics that facilitate an active lifestyle with excellent quality of life. For these patients there is a renewed interest for the use of PA as an ideal substitute in AVR and Ross procedure can be considered to support its use in selected young and middle-aged adults with an aortic valve infection (42-45).
Implantation of the PA in the setting of IE can be performed using two main techniques $(46,47)$. The subcoronary technique may be used for localized infection limited to aortic leaflet and partial involvement of aortic annulus alongside root replacement that may be performed when the infection is extended to the aortic root. The subcoronary insertion has the advantage of limiting the surface of PA exposed to the higher systemic pressures and consequent dilation of vessel wall $(46,47)$. Numerous surgeons prefer to perform the Ross procedure with full root replacement technique and inclusion technique especially in bicuspid/ unicuspid aortic valves or in the presence of AI which is marked in aortic IE. A limited number of randomized trials (Level I/Class recommendation A) are available to support performing the Ross Operation in the setting of aortic IE (48-55).

Recently, Ratschiller et al. (56) reported the use of Ross procedure in a series of 190 patients. The operation was performed by means of freestanding root replacement technique and 19 patients had acute endocarditis as the indication for operation including 6 patients with bicuspid aortic valves. The clinical follow-up was $100 \%$ complete and with a mean of $12.0 \pm 5.7$ years. The results showed lower in-hospital mortality (5.3\%). Echocardiography at hospital discharge revealed at most trivial aortic regurgitation in all patients with no cases of infection relapse that affected the autograft. One patient ( $0.4 \%$ per patient-year) was reoperated 1.8 years after the Ross procedure for endocarditis affecting the pulmonary homograft. The major concern in these patients was the expansion with failure of PA that was noted in three patients (15.8\%) for which reoperation was required. The Ross procedure has proven safety and effectiveness as an alternative to prosthetic valve replacement or homograft implantation in selected young patients with acute endocarditis with a low rate infection recurrence (56).

\section{Comments}

We reported the use of cryopreserved homograft for AVR in 210 patients (9) either using a free-hand subcoronary implantation technique or as root replacement with coronary reimplantation (Figure $2 A, B$ ). More than half of the patients had endocarditis, with $21 \%$ showing evidence of abscess formation (Figure 2C) and nearly a quarter had associated valvular or coronary procedures. Although the comparison of the two techniques was not our primary objective, we did not find significant differences between 
A

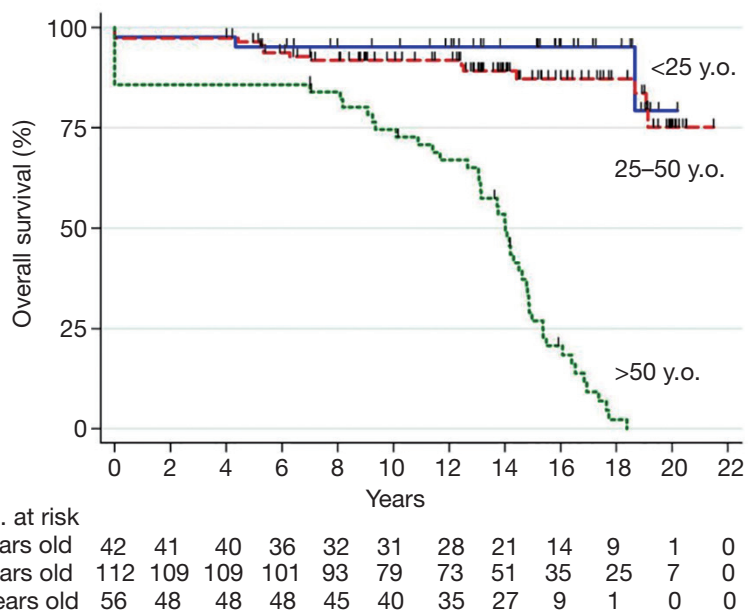

B

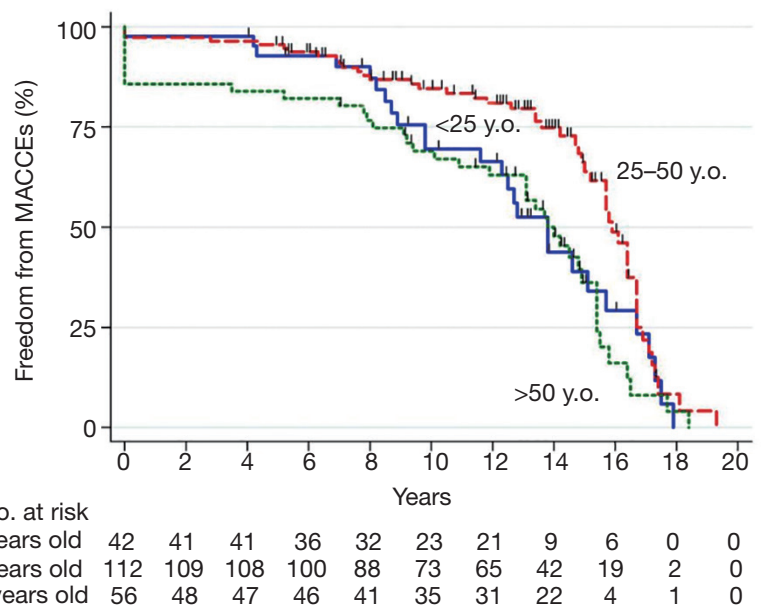

C

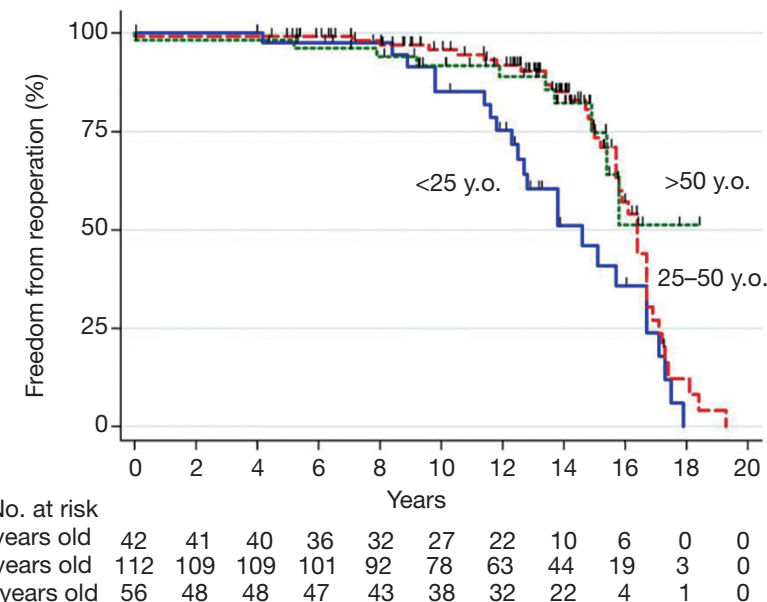

Figure 2 Endpoints among age groups. (A) Overall survival; (B) freedom from MACCEs; (C) freedom from reoperation. MACCE, major adverse cardiac and cerebrovascular events.

the choice of surgical insertion. The use of Ao-Homo was associated with an overall mortality and cardiac mortality rate of $38.1 \%$ and $30.5 \%$ respectively, and the rate of structural valve deterioration requiring repeat surgery was $27.1 \%$. There was no early recurrence of infection with only 4 late recurrence of endocarditis. The composite outcome of major adverse cardiac and cerebrovascular events (MACCE) (all valve-related mortality, valverelated morbidity, thrombosis, bleeding, neurologic events, endocarditis, rehospitalization for heart failure, and worsening New York Heart Association class) was $50.6 \% \pm 4.1 \%$ at 15 years. The use of allogenic tissue was also associated with no difference in clinical outcomes between pregnant women and the other patients (9). Our results were similar to the findings of the Cleveland Clinic and another study from Sweden $(57,58)$. We also used the PA as a substitute for AVR in IE in limited cases (young and middle-aged patients with both bicuspid and tricuspid valve anatomy). In our series, no cases of recurrent PA endocarditis occurred at up to 23 years of follow-up which was unique to our center (59) (Figure 2).

The clinical benefits associated with the use of AoHomo or PA were more evident in women with future plans for pregnancy. Pregnancy gravidity was not found to be a significant effect modifier on the functionality of allogenic tissue. This finding was confirmed by Romeo et al. (14) who described the use of homograft as a conduit for right ventricular outflow tract (RVOT) reconstruction in women with future plans for pregnancy. All women survived pregnancy, $20.2 \%$ and $23.8 \%$ of newborn were small for 

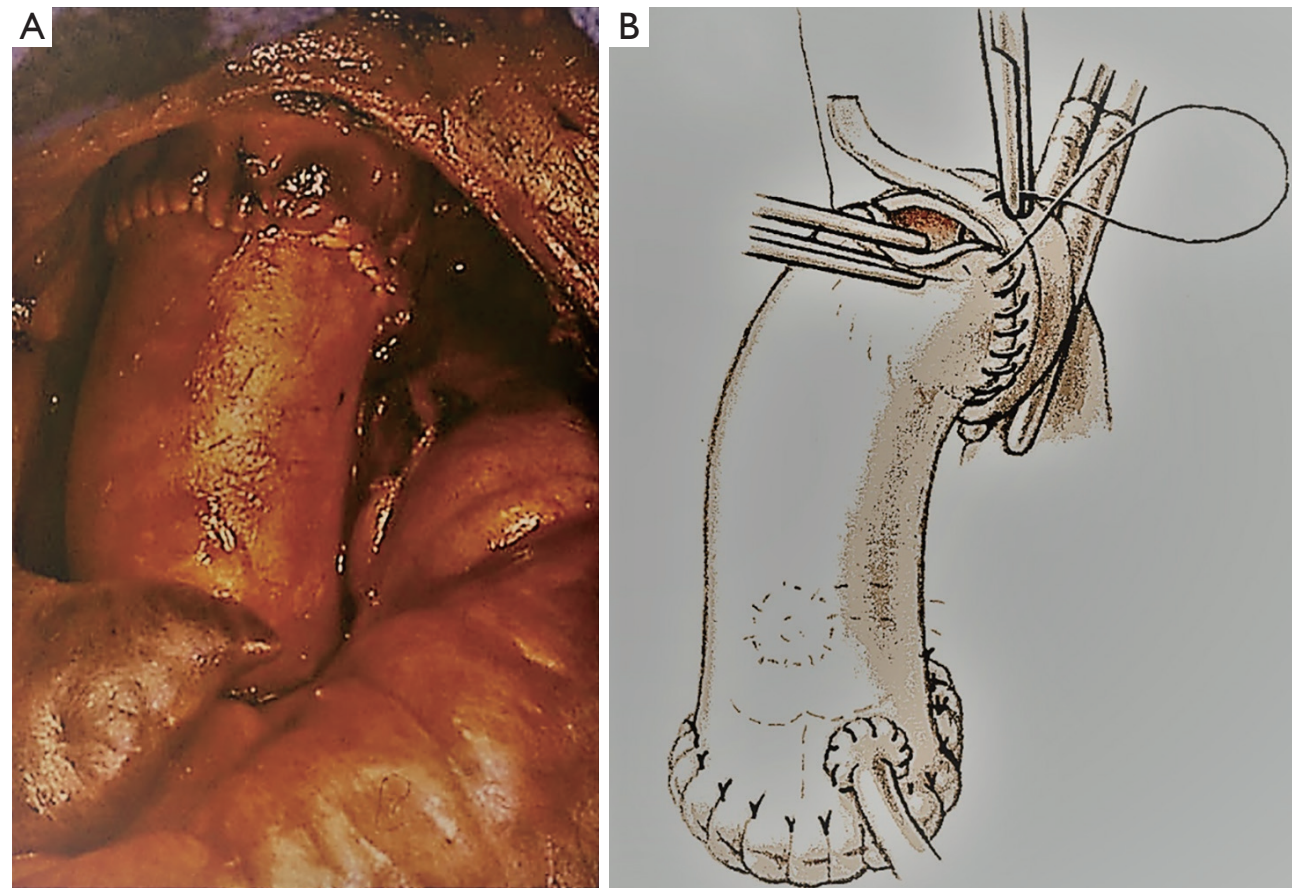

Figure 3 Valve endocarditis following the Bentall procedure replacement of the valved conduit with a homograft including the whole ascending aorta (A) or the $\operatorname{arch}(\mathrm{B})$.

gestational age or premature. These results $(9,14)$ offers a biologic mechanism to explain the observed advantage in clinical outcomes; however, the higher incidence of preterm delivery and children small for gestational age deserves further in-depth investigations (14,42-44).

Safety and effectiveness of allogenic and autologous substitutes over conventional prosthesis in recurrence of endocarditis has been widely reported in several observational studies, although a difference in resistance to infection between the valve and aortic wall of allogenic tissue noted (increased resistance in homograft ascending aorta tissues) (15-17,36,37). It is possible that the adaptive remodeling allows the $\mathrm{PA}$ to mimic the highly refined anatomical changes and function of the neo-aortic root which intervenes as a protective mechanism both in the leaflet and in PA wall (60). The remodeling process is largely mediated by valvular endothelial and interstitial cells, which undergo activation and phenotypic changes when exposed to the systemic circulation providing greater resistance to the leaflets (60-62).

Re-do surgery in cases of re-infection is particularly challenging with increased risks of morbidity and mortality (1,9,30-34). Infection relapse involving synthetic prostheses or prosthetic materials are daunting and more technically demanding than infection relapse of a homograft valve replacement. We noted that extensive adhesiolysis was necessary to access the heart when synthetic material is implanted compared to homografts $(9,26)$. Our experience also revealed that the foreign material constituting the stent of mechanical or biological prosthetic valves evokes a strong inflammatory reaction and might cause denser adhesions complicating the operation $(9,23,26)$ (Figure 3).

Several limiting factors to using Ao-Homo and PA probably come from patient choice, influenced by the surgeon who has to ethically weigh up the risk of failure of the procedure and re-operation, which are not infrequent $(9,18-20,50,63)$. For example, when a PA is used, external reinforcement of the PA with a prosthetic Dacron graft has been proposed to circumvent its late expansion but data on the long-term results of this approach are lacking (64). Nonetheless, experimental models of the Ross operation have shown the risk of migration of polyester into the PA wall with the development of complications related to the onset of the immune-inflammatory processes and to the biomechanical impairment of the PA (65-68). Some recent studies have shown a high adaptability to remodeling of PA when systemic pressures exert unexpected wall 
stressors. The phenomenon of remodeling can be induced by polyesters with gradual reabsorption favoring a process of neo-arterialization (69-71). Wall cells of PAs implanted in the aortic position start expressing Ki67, a marker of proliferation and differentiation that leads to extracellular matrix remodeling, in the form of increased smooth muscle actin production (60). These results pave the way for the use of semi-absorbable scaffolds that have the dual effect of avoiding the expansion of the neoaortic root while providing greater solidity to the wall $(61,62,69)$.

Finally, the heart team discussion cannot neglect the patient's preference. A very extensive operation might be a daunting prospect for patients. Clinicians should detail the steps of the procedure, the potential complications and the postoperative course to facilitated informed consent and decision-making $(3,23)$. Patients should be made aware of the complexity of the disease and on the potential need of extensive debridement to achieve good and stable results. The risk of reoperation for SVD of Ao-Homo or PA failure must weighted against the durability of the bioprosthetic valve as an alternative to allogenic or autologous tissue $(9,10,18-20,50,63)$.

Five main points are required for guiding the choice of valvular substitute for AVE during the process of shared decision-making that includes the patient, the patient's family, a cardiologist, a cardiac surgeon, and ideally, the patient's general cardiologist or primary care physician:

(I) The technical issues involving Ao-Homo or PA usage that may pose difficulties during surgery (especially in young patients);

(II) The age of the patient may guide the choice of the prosthesis even in complex valve endocarditis and widely infected field when allogenic or autologous tissue are recommended;

(III) The risk for a repeat operation when the use of AoHomos or PAs is preferred over the conventional prostheses;

(IV) The use of allogenic or autologous valve substitute is beneficial if there is a high risk of recurrence of infection, avoiding extensive adhesiolysis and debridement of synthetic material;

(V) The rule of societies including religious education that may impose restrictions on the use of allogenic or autologous valve substitute.

\section{Acknowledgments}

None.

\section{Footnote}

Conflicts of Interest: The authors have no conflicts of interest to declare.

Ethical Statement: The authors are accountable for all aspects of the work in ensuring that questions related to the accuracy or integrity of any part of the work are appropriately investigated and resolved.

\section{References}

1. David TE, Gavra G, Feindel CM, et al. Surgical treatment of active infective endocarditis: a continued challenge. J Thorac Cardiovasc Surg 2007;133:144-9.

2. Manne MB, Shrestha NK, Lytle BW, et al. Outcomes after surgical treatment of native and prosthetic valve infective endocarditis. Ann Thorac Surg 2012;93:489-93.

3. Nishimura RA, Otto CM, Bonow RO, et al. 2017 AHA/ ACC Focused Update of the 2014 AHA/ACC Guideline for the Management of Patients With Valvular Heart Disease: A Report of the American College of Cardiology/ American Heart Association Task Force on Clinical Practice Guidelines. Circulation 2017;135:e1159-95.

4. Cahill TJ, Baddour LM, Habib G, et al. Challenges in Infective Endocarditis. J Am Coll Cardiol 2017;69:325-44.

5. Selton-Suty C, Celard M, Le Moing V, et al. Preeminence of Staphylococcus aureus in infective endocarditis: a 1-year population-based survey. Clin Infect Dis 2012;54:1230-9.

6. Duval X, Delahaye F, Alla F, et al. Temporal trends in infective endocarditis in the context of prophylaxis guideline modifications: three successive population-based surveys. J Am Coll Cardiol 2012;59:1968-76.

7. Ammerlaan HS, Harbarth S, Buiting AG, et al. Secular trends in nosocomial bloodstream infections: antibioticresistant bacteria increase the total burden of infection. Clin Infect Dis 2013;56:798-805.

8. Correa de Sa DD, Tleyjeh IM, Anavekar NS, et al. Epidemiological trends of infective endocarditis: a population-based study in Olmsted County, Minnesota. Mayo Clin Proc 2010;85:422-6.

9. Nappi F, Nenna A, Petitti T, et al. Long-term outcome of cryopreserved allograft for aortic valve replacement. J Thorac Cardiovasc Surg 2018;156:1357-65.e6.

10. Jassar AS, Bavaria JE, Szeto WY, et al. Graft selection for aortic root replacement in complex active endocarditis: does it matter? Ann Thorac Surg 2012;93:480-7.

11. Perrotta S, Lentini S. In patients with severe active 
aortic valve endocarditis, is a stentless valve as good as the homograft? Interact Cardiovasc Thorac Surg 2010;11:309-13.

12. Sweeney MS, Reul GJ, Jr., Cooley DA, et al. Comparison of bioprosthetic and mechanical valve replacement for active endocarditis. J Thorac Cardiovasc Surg 1985;90:676-80.

13. Klieverik LM, Yacoub MH, Edwards S, et al. Surgical treatment of active native aortic valve endocarditis with allografts and mechanical prostheses. Ann Thorac Surg 2009;88:1814-21.

14. Romeo JLR, Takkenberg JJM, Roos-Hesselink JW, et al. Outcomes of Pregnancy After Right Ventricular Outflow Tract Reconstruction With an Allograft Conduit. J Am Coll Cardiol 2018;71:2656-65.

15. Arabkhani B, Bekkers JA, Andrinopoulou ER, et al. Allografts in aortic position: Insights from a 27-year, single-center prospective study. J Thorac Cardiovasc Surg 2016;152:1572-9.e3.

16. Fukushima S, Tesar PJ, Pearse B, et al. Long-term clinical outcomes after aortic valve replacement using cryopreserved aortic allograft. J Thorac Cardiovasc Surg 2014;148:65-72.e2.

17. O'Brien MF, Harrocks S, Stafford EG, et al. The homograft aortic valve: a 29-year, $99.3 \%$ follow up of 1,022 valve replacements. J Heart Valve Dis 2001;10:334-44; discussion 335.

18. Bekkers JA, Klieverik LM, Raap GB, et al. Re-operations for aortic allograft root failure: experience from a 21year single-center prospective follow-up study. Eur J Cardiothorac Surg 2011;40:35-42.

19. Joudinaud TM, Baron F, Raffoul R, et al. Redo aortic root surgery for failure of an aortic homograft is a major technical challenge. Eur J Cardiothorac Surg 2008;33:989-94.

20. Kowert A, Vogt F, Beiras-Fernandez A, et al. Outcome after homograft redo operation in aortic position. Eur J Cardiothorac Surg 2012;41:404-8.

21. Byrne JG, Rezai K, Sanchez JA, et al. Surgical management of endocarditis: the society of thoracic surgeons clinical practice guideline. Ann Thorac Surg 2011;91:2012-9.

22. Pettersson GB, Coselli JS, Pettersson GB, et al. 2016 The American Association for Thoracic Surgery (AATS) consensus guidelines: Surgical treatment of infective endocarditis: Executive summary. J Thorac Cardiovasc Surg 2017;153:1241-58.e29.

23. Nappi F, Spadaccio C, Dreyfus J, et al. Mitral endocarditis: A new management framework. J Thorac Cardiovasc Surg 2018;156:1486-95.e4.

24. Nappi F, Spadaccio C, Acar C. Use of allogeneic tissue to treat infective valvular disease: Has everything been said? J Thorac Cardiovasc Surg 2017;153:824-8.

25. Nappi F, Spadaccio C. Simplest solutions are not always the cleverest: Can we stitch in an infected annulus? Should we rethink the current guidelines? J Thorac Cardiovasc Surg 2017;154:1899-900.

26. Olivito S, Lalande S, Nappi F, et al. Structural deterioration of the cryopreserved mitral homograft valve. J Thorac Cardiovasc Surg 2012;144:313-20, 20.e1.

27. Acar C. Monobloc or separate aortic and mitral homografts?. J Thorac Cardiovasc Surg 2006;132:442-3; author reply 443.

28. Bando K. Proposal for building an infrastructure for international randomized, control trials and a comprehensive registry of infective endocarditis. J Thorac Cardiovasc Surg 2018;155:73-4.

29. Nappi F, Spadaccio C. keep fumbling around in the dark when it comes to infective endocarditis, or produce new, reliable data to redesign the guidelines? J Thorac Cardiovasc Surg 2018;155:75-6.

30. Musci M, Weng Y, Hubler M, et al. Homograft aortic root replacement in native or prosthetic active infective endocarditis: twenty-year single-center experience. J Thorac Cardiovasc Surg 2010;139:665-73.

31. Kim JB, Ejiofor JI, Yammine M, et al. Are homografts superior to conventional prosthetic valves in the setting of infective endocarditis involving the aortic valve? J Thorac Cardiovasc Surg 2016;151:1239-46, 1248.e1-2.

32. Moon MR, Miller DC, Moore KA, et al. Treatment of endocarditis with valve replacement: the question of tissue versus mechanical prosthesis. Ann Thorac Surg 2001;71:1164-71.

33. Kim JB, Ejiofor JI, Yammine M, et al. Surgical outcomes of infective endocarditis among intravenous drug users. J Thorac Cardiovasc Surg 2016;152:832-41.e1.

34. Yankah AC, Klose H, Petzina R, et al. Surgical management of acute aortic root endocarditis with viable homograft: 13-year experience. Eur J Cardiothorac Surg 2002;21:260-7.

35. Lalani T, Chu VH, Park LP, et al. In-hospital and 1 -year mortality in patients undergoing early surgery for prosthetic valve endocarditis. JAMA Intern Med 2013;173:1495-504.

36. Steffen V, Marsch G, Burgwitz K, et al. Resistance to infection of long-term cryopreserved human aortic valve allografts. J Thorac Cardiovasc Surg 2016;151:1251-9. 
37. Camiade C, Goldschmidt P, Koskas F, et al. Optimization of the resistance of arterial allografts to infection: comparative study with synthetic prostheses. Ann Vasc Surg 2001;15:186-96.

38. Kuehn C, Graf K, Mashaqi B, et al. Prevention of early vascular graft infection using regional antibiotic release. J Surg Res 2010;164:e185-91.

39. Zander J, Maier B, Zoller M, et al. Effects of biobanking conditions on six antibiotic substances in human serum assessed by a novel evaluation protocol. Clin Chem Lab Med 2016;54:265-74.

40. Nappi F, Spadaccio C, Chello M, et al. The Ross procedure: Underuse or under-comprehension? J Thorac Cardiovasc Surg 2015;149:1463-4.

41. Sharabiani MT, Dorobantu DM, Mahani AS, et al. Aortic Valve Replacement and the Ross Operation in Children and Young Adults. J Am Coll Cardiol 2016;67:2858-70.

42. Bouhout I, Poirier N, Mazine A, et al. Cardiac, obstetric, and fetal outcomes during pregnancy after biological or mechanical aortic valve replacement. Can J Cardiol 2014;30:801-7.

43. D'Souza R, Ostro J, Shah PS, et al. Anticoagulation for pregnant women with mechanical heart valves: a systematic review and meta-analysis. Eur Heart J 2017;38:1509-16.

44. Steinberg ZL, Dominguez-Islas CP, Otto CM, et al. Maternal and Fetal Outcomes of Anticoagulation in Pregnant Women With Mechanical Heart Valves. J Am Coll Cardiol 2017;69:2681-91.

45. El-Hamamsy I, Eryigit Z, Stevens LM, et al. Longterm outcomes after autograft versus homograft aortic root replacement in adults with aortic valve disease: a randomised controlled trial. Lancet 2010;376:524-31.

46. Ross DN. Replacement of aortic and mitral valves with a pulmonary autograft. Lancet 1967;2:956-8.

47. Sievers HH, Stierle U, Charitos EI, et al. A multicentre evaluation of the autograft procedure for young patients undergoing aortic valve replacement: update on the German Ross Registrydagger. Eur J Cardiothorac Surg 2016;49:212-8.

48. Skillington PD, Mokhles MM, Takkenberg JJ, et al. The Ross procedure using autologous support of the pulmonary autograft: techniques and late results. J Thorac Cardiovasc Surg 2015;149:S46-52.

49. Reece TB, Welke KF, O'Brien S, et al. Rethinking the ross procedure in adults. Ann Thorac Surg 2014;97:175-81.

50. Klieverik LM, Takkenberg JJ, Bekkers JA, et al. The Ross operation: a Trojan horse? Eur Heart J 2007;28:1993-2000.
51. Mazine A, Ghoneim A, El-Hamamsy I. The Ross Procedure: How I Teach It. Ann Thorac Surg 2018;105:1294-8.

52. David TE. Aortic Valve Replacement with Pulmonary Autograft: Subcoronary and Aortic Root Inclusion Techniques. Operative Techniques in Thoracic and Cardiovascular Surgery 2012;17:27-40.

53. Berdajs DA, Muradbegovic M, Haselbach D, et al. Ross procedure: is the root replacement technique superior to the sub-coronary implantation technique? Long-term results. Eur J Cardiothorac Surg 2014;46:944-51.

54. David TE, Omran A, Ivanov J, et al. Dilation of the pulmonary autograft after the Ross procedure. J Thorac Cardiovasc Surg 2000;119:210-20.

55. David TE, Woo A, Armstrong S, et al. When is the Ross operation a good option to treat aortic valve disease? J Thorac Cardiovasc Surg 2010;139:68-73; discussion 73-5.

56. Ratschiller T, Sames-Dolzer E, Paulus P, et al. Longterm Evaluation of the Ross Procedure in Acute Infective Endocarditis. Semin Thorac Cardiovasc Surg 2017;29:494-501.

57. Perrotta S, Jeppsson A, Frojd V, et al. Surgical Treatment of Aortic Prosthetic Valve Endocarditis: A 20-Year SingleCenter Experience. Ann Thorac Surg 2016;101:1426-32.

58. Flameng W, Daenen W, Jashari R, et al. Durability of homografts used to treat complex aortic valve endocarditis. Ann Thorac Surg 2015;99:1234-8.

59. Nappi F, Nenna A, Larobina D, et al. Simulating the ideal geometrical and biomechanical parameters of the pulmonary autograft to prevent failure in the Ross operation. Interact Cardiovasc Thorac Surg 2018;27:269-76.

60. Nappi F, Fraldi M, Spadaccio C, et al. Biomechanics drive histological wall remodeling of neoaortic root: $\mathrm{A}$ mathematical model to study the expression levels of ki 67 , metalloprotease, and apoptosis transition. J Biomed Mater Res A 2016;104:2785-93.

61. Nappi F, Spadaccio C, Al-Attar N, et al. The Ross procedure at the crossroads: lessons from biology: is Dr Ross's dream concluded? Int J Cardiol 2015;178:37-9.

62. Spadaccio C, Montagnani S, Acar C, et al. Introducing bioresorbable scaffolds into the show. A potential adjunct to resuscitate Ross procedure. Int J Cardiol 2015;190:50-2.

63. Stulak JM, Burkhart HM, Sundt TM, 3rd, et al. Spectrum and outcome of reoperations after the Ross procedure. Circulation 2010;122:1153-8.

64. Carrel T. The autograft inclusion: an obligatory step to avoid late failure following the Ross procedure? J Thorac 
Cardiovasc Surg 2015;149:S53-4.

65. Nappi F, Spadaccio C, Castaldo C, et al. Reinforcement of the pulmonary artery autograft with a polyglactin and polydioxanone mesh in the Ross operation: experimental study in growing lamb. J Heart Valve Dis 2014;23:145-8.

66. Nappi F, Spadaccio C, Fouret P, et al. An experimental model of the Ross operation: Development of resorbable reinforcements for pulmonary autografts. J Thorac Cardiovasc Surg 2015;149:1134-42.

67. Spadaccio C, Nappi F, Al-Attar N, et al. Old Myths, New Concerns: the Long-Term Effects of Ascending Aorta Replacement with Dacron Grafts. Not All That Glitters Is Gold. J Cardiovasc Transl Res 2016;9:334-42.

68. Spadaccio C, Nappi F, De Marco F, et al. Preliminary In Vivo Evaluation of a Hybrid Armored Vascular Graft

Cite this article as: Nappi F, Singh SSA, Lusini M, Nenna A, Gambardella I, Chello M. The use of allogenic and autologous tissue to treat aortic valve endocarditis. Ann Transl Med 2019;7(18):491. doi: 10.21037/atm.2019.08.76
Combining Electrospinning and Additive Manufacturing Techniques. Drug Target Insights 2016;10:1-7.

69. Nappi F, Spadaccio C, Fraldi M, et al. A composite semiresorbable armoured scaffold stabilizes pulmonary autograft after the Ross operation: Mr Ross's dream fulfilled. J Thorac Cardiovasc Surg 2016;151:155-64.e1.

70. Nappi F, Carotenuto AR, Di Vito D, et al. Stress-shielding, growth and remodeling of pulmonary artery reinforced with copolymer scaffold and transposed into aortic position. Biomech Model Mechanobiol 2016;15:1141-57.

71. Nappi F, Carotenuto AR, Cutolo A, et al. Compliance mismatch and compressive wall stresses drive anomalous remodelling of pulmonary trunks reinforced with Dacron grafts. J Mech Behav Biomed Mater 2016;63:287-302. 